\title{
Breast Cancer Characteristics Associated With Digital Versus Film-Screen Mammography for Screen-Detected and Interval Cancers
}

\section{Louise M. Henderson ${ }^{1}$ \\ Diana L. Miglioretti² \\ Karla Kerlikowske ${ }^{3}$ \\ Karen J. Wernli ${ }^{4}$ \\ Brian L. Sprague ${ }^{5}$ \\ Constance D. Lehman ${ }^{6}$}

\begin{abstract}
Keywords: digital mammography, film mammography, interval cancer, screen-detected cancer

DOI:10.2214/AJR.14.13904

Received October 2, 2014; accepted after revision February 23, 2015.

The content is solely the responsibility of the authors and does not necessarily represent the official views of the National Cancer Institute or the National Institutes of Health.
\end{abstract}

C. D. Lehman has received grant support from $\mathrm{GE}$ Healthcare and is a member of the Comparative Effectiveness Research Advisory Board for GE Healthcare.

Supported by the National Cancer Institute-funded Breast Cancer Surveillance Consortium (HHSN261201100031C), a National Cancer Institute-funded Risk-Based Breast Cancer Screening in Community Settings grant (P01CA154292), and a National Cancer Institute-funded Vermont Population-Based Research Optimizing Screening Through Personalized Regimens grant (U54 CA163303). The collection of cancer and vital status data used in this study was supported in part by several state public health departments and cancer registries throughout the United States. A full description of these sources is available at the Breast Cancer Surveillance Consortium website.

\section{AJR2015; 205:676-684}

0361-803X/15/2053-676

(c) American Roentgen Ray Society
OBJECTIVE. The purpose of this study was to determine whether pathologic findings of screen-detected and interval cancers differ for digital versus film mammography.

MATERIALS AND METHODS. Breast Cancer Surveillance Consortium data from 2003-2011 on 3,021,515 screening mammograms (40.3\% digital, 59.7\% film) of women 4089 years old were reviewed. Cancers were considered screen detected if diagnosed within 12 months of an examination with positive findings and interval if diagnosed within 12 months of an examination with negative findings. Tumor characteristics for screen-detected and interval cancers were compared for digital versus film mammography by use of logistic regression models to estimate the odds ratio and 95\% CI with adjustment for age, race and ethnicity, hormone therapy use, screening interval, examination year, and registry. Generalized estimating equations were used to account for correlation within facilities.

RESULTS. Among 15,729 breast cancers, $85.3 \%$ were screen detected and $14.7 \%$ were interval. Digital and film mammography had similar rates of screen-detected (4.47 vs 4.42 per 1000 examinations) and interval ( 0.73 vs 0.79 per 1000 examinations) cancers for digital versus film. In adjusted analyses, interval cancers diagnosed after digital examinations with negative findings were less likely to be American Joint Committee on Cancer stage IIB or higher (odds ratio, $0.69 ; 95 \% \mathrm{CI}, 0.52-0.93$ ), have positive nodal status (odds ratio, $0.78 ; 95 \% \mathrm{CI}$, 0.64-0.95), or be estrogen receptor negative (odds ratio, $0.71 ; 95 \% \mathrm{CI}, 0.56-0.91$ ) than were interval cancers diagnosed after a film examination with negative findings.

CONCLUSION. Screen-detected cancers diagnosed after digital and film mammography had similar rates of unfavorable tumor characteristics. Interval-detected cancers diagnosed after a digital examination were less likely to have unfavorable tumor features than those diagnosed after film mammography, but the absolute differences were small.

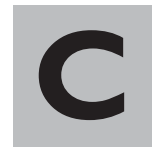

ompared with screen-detected cancers, interval cancers are more likely to be large, poorly differentiated, and estrogen-receptor negative and to have lymph node involvement [1]. Hence, interval cancers typically present with a worse prognosis than do screen-detected cancers. Most studies examining tumor characteristics of screen-detected versus interval cancers have focused on women undergoing screening with film mammography [2-6].

In the United States, digital mammography has rapidly replaced film mammogra- phy; approximately 94\% of accredited mammography units were digital as of March 1, 2014 [7]. How this transition to digital technology has affected screen-detected versus interval cancer rates is unclear. In particular, the extent to which tumor characteristics of screen-detected versus interval cancers differ by imaging modality has, to our knowledge, not been studied in the United States. Using national Breast Cancer Surveillance Consortium (BCSC) data from 2000 to 2006, Kerlikowske et al. [8] found no differences in distribution of cancer stage, tumor

\footnotetext{
1Department of Radiology, The University of North Carolina at Chapel Hill, 130 Mason Farm Rd, 3124 Bioinformatics Building, CB 7515, Chapel Hill, NC 27599. Address correspondence to L. M. Henderson (Louise_Henderson@med.unc.edu).

${ }^{2}$ Division of Biostatistics, Department of Public Health Sciences, University of California, Davis, Davis, CA.

${ }^{3}$ Departments of Medicine and Epidemiology and Biostatistics, University of California, San Francisco, CA.

${ }^{4}$ Group Health Research Institute, Seattle, WA.

${ }^{5}$ Department of Surgery, University of Vermont, Burlington, VT.

${ }^{6}$ Department of Radiology, University of Washington, Seattle Cancer Care Alliance, Seattle, WA.
} 
size, nodal status, or tumor grade for digital versus film, but the analysis was not stratified by screen-detected versus interval cancer. The investigators did report that digital mammography had a higher sensitivity in the detection of estrogen receptor-negative tumors than did film-screen mammography. A 2014 study from The Netherlands [9] examined the pathologic findings of interval cancers for digital versus film mammography. The study showed that the tumor characteristics were comparable, but it is unclear whether similar patterns exist in the United States.

The purpose of our study was to examine and compare tumor characteristics of screendetected and interval cancers by imaging modality (digital versus film) among women undergoing community-based mammographic screening in the United States.

\section{Materials and Methods \\ Data Sources}

The data for this study were collected from six registries that participate in the BCSC: Carolina Mammography Registry, Group Health Cooperative (Washington State), New Hampshire Mammography Network, New Mexico Mammography Project, San Francisco Mammography Registry, and the Vermont Breast Cancer Surveillance System [10]. The prospective data collected from participating BCSC mammography practices include patient self-reported demographic characteristics, indication for breast imaging visit, breast cancer risk factors, mammographic assessment, and management recommendations. These data are linked with tumor information from pathology databases and regional cancer registry data. Each registry site submits data to a statistical coordinating center for quality control checks and pooled analyses. Each registry and the statistical coordinating center received institutional review board approval for either active or passive consent or a waiver of consent to enroll participants, link study data, and perform analytic studies. All procedures were HIPAA compliant, and all registries received a federal certificate of confidentiality.

\section{Study Population}

We included mammograms of women 40-89 years old obtained from 2003 to 2011 for which the indication was screening as noted by the radiologist or technologist [11]. We excluded mammograms of women with a previous breast cancer diagnosis, mastectomy, or implants. We also excluded data from eight Fuji Computed Radiography Mammography Suite machines (3.9\% of the data) because the sensitivity of computed radiography is lower than that of digital direct radiogra-

\section{Digital Versus Film-Screen Mammography}

phy and because almost all digital mammography machines in current use are digital direct radiography systems. To avoid misclassifying diagnostic examinations as screening, we excluded examinations of patients who had undergone mammography or breast ultrasound in the previous 9 months or in which only unilateral mages were obtained. The final study examinations included 3,021,515 screening mammograms, of which 1,218,314 (40.3\%) were digital examinations and 1,803,201 (59.7\%) were film examinations.

\section{Definitions}

Women were considered to have incident breast cancer if a diagnosis of invasive carcinoma or ductal carcinoma in situ (DCIS) was made within 12 months of the screening mammogram and before the next screening mammogram [12]. Invasive cancers were further categorized according to American Joint Committee on Cancer (AJCC), sixth edition, stage; Surveillance Epidemiology End Result (SEER) summary stage; grade; tumor size at the time of pathologic examination; lymph node status; and hormone receptor status.

Each screening mammographic interpretation was classified as positive or negative on the basis of radiologists' BI-RADS screening assessments. We defined a positive interpretation as BI-RADS category 0 (additional imaging required), 4 (needs evaluation), or 5 (highly suggestive of malignancy) or as BI-RADS 3 (probably benign) when the recommendation was for immediate workup. We defined a negative interpretation as BI-RADS category 1 (negative) or 2 (benign finding) or as BI-RADS 3 (probably benign) with no recommendation for immediate additional imaging [13, 14]. We categorized the BI-RADS 3 assessments in this manner to account for the differences in how some practicing radiologists use BI-RADS category 3 with additional imaging recommended instead of using BI-RADS category $0[13,15]$. We defined screen-detected cancers as those diagnosed within 12 months of a screening mammographic examination with a positive finding and before the next screening examination. We defined interval cancers as those diagnosed within 12 months of a negative screening mammographic result and before the next screening examination.

\section{Statistical Analyses}

We examined the distribution of patient characteristics and compared the tumor characteristics of screen-detected versus interval cancers by imaging modality. To obtain estimates of the odds ratios (ORs) of the presence of favorable and unfavorable tumor characteristics for digital versus film by mode of detection, we fit two separate logistic regression models. We accounted for cor- relation within facilities by using generalized estimating equations. We separately modeled the rates of cancers with favorable and unfavorable tumor characteristics among all women, regardless of cancer status. We adjusted the models for age, race and ethnicity, current hormone therapy use, time since last mammogram (i.e., the mammogram before the one used in this study), examination year, and registry site. We excluded examinations with unknown covariates from the logistic regression models. All analyses were performed with SAS software (version 9.2, SAS Institute).

\section{Results \\ Patient Characteristics for \\ Screening Mammograms}

The digital $(n=1,218,314)$ and film $(n=$ $1,803,201)$ examination groups had similar distributions of age, family history of breast cancer, menopausal status, history of breast biopsy, BI-RADS breast density, and BI-RADS category (Table 1). Asian patients were more likely to undergo digital mammography, and Hispanic patients were more likely to undergo film mammography. There was less hormone therapy use among women undergoing digital mammography. Women undergoing digital examinations were more likely to have undergone mammography within the previous year than were women undergoing film examinations $(69 \%$ versus $61 \%$ ). The uptake of digital mammography is evident from the distribution of examination years by imaging modality during the study period. Similar proportions of digital and film examinations resulted in screen-detected $(0.44 \%$ for both) and interval cancers $(0.073 \%$ and $0.079 \%)$ for both modalities.

\section{Patient Characteristics of Screen-Detected and Interval Cancers}

A total of 15,729 breast cancers were diagnosed in the 12 months of follow-up after the screening mammographic examination and before the next one; $85.3 \%(n=13,418)$ of these cancers were screen detected and $14.7 \%(n=2311)$ were interval cancers. Of the screen-detected cancers, $5441(40.6 \%)$ were in the digital and 7977 (59.4\%) were in the film examination group (Table 2). For interval cancers, $895(38.7 \%)$ were in the digital and $1416(61.3 \%)$ were in the film examination group. Compared with screen-detected cancers and regardless of imaging modality, interval cancers were found in higher proportion among younger women, premenopausal or perimenopausal women, women with a history of breast biopsy, women with dense 


\section{Henderson et al.}

breasts, and women who had undergone screening in the previous 12 months.

Tumor Characteristics of Screen-Detected and Interval Cancers

The screen-detected cancer rates per 1000 examinations were similar for digital and film mammography (4.47 and 4.42), as was the interval cancer rate $(0.73$ and 0.79 per 1000 examinations) (Table 3). Interval cancers were more likely to have unfavorable tumor characteristics regardless of imaging modality. Specifically, interval cancers were more likely to be invasive, stage
IIB or higher; be in a SEER summary regional or distant stage; be larger than 20 $\mathrm{mm}$; have positive nodal status; be grade III; and be estrogen or progesterone receptor negative. Screen-detected cancers identified with digital mammography were more likely to be DCIS than were those detected

TABLE I: Characteristics of Patients Undergoing Screening Mammographic Examinations

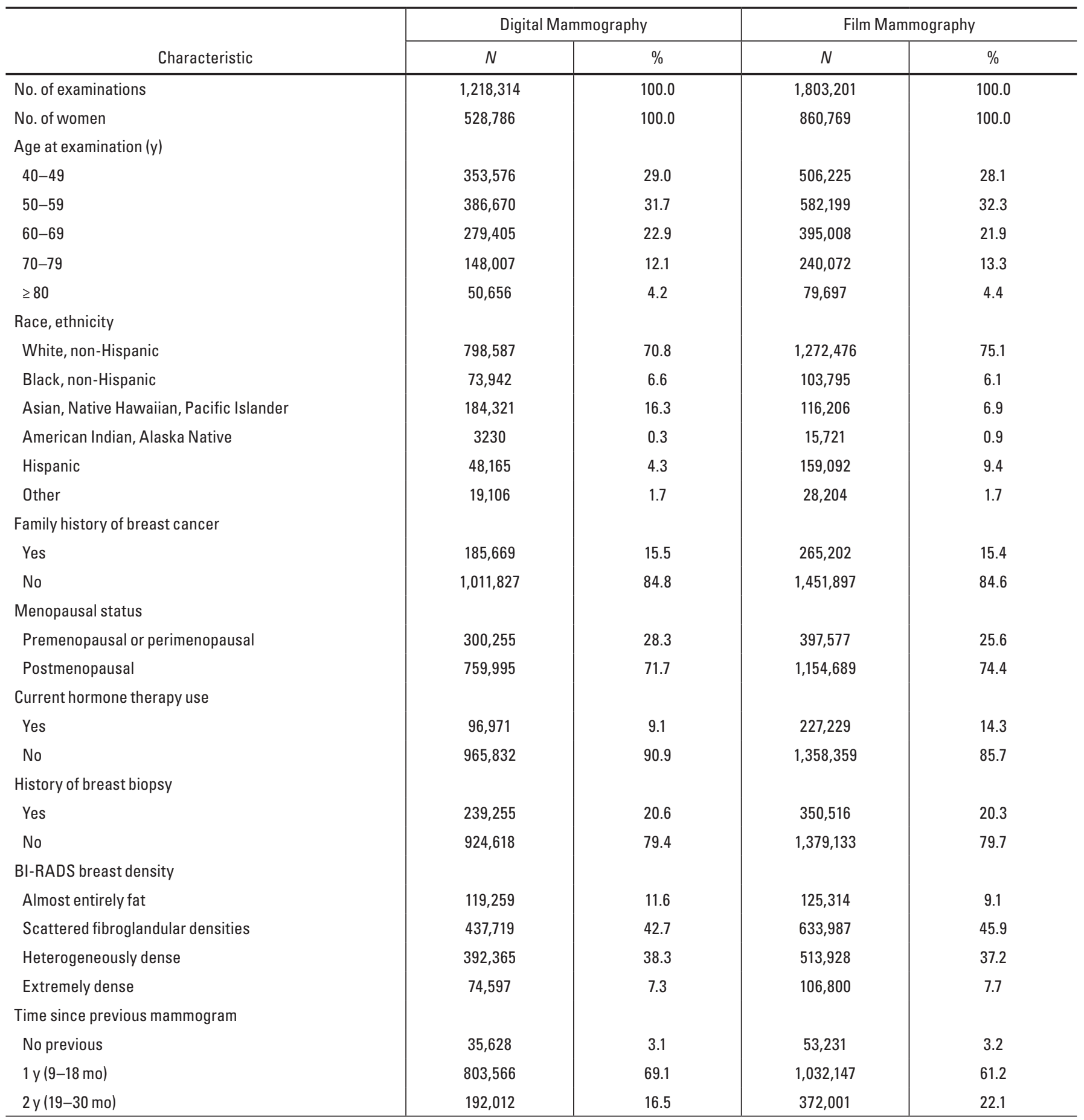


Digital Versus Film-Screen Mammography

TABLE I: Characteristics of Patients Undergoing Screening Mammographic Examinations (continued)

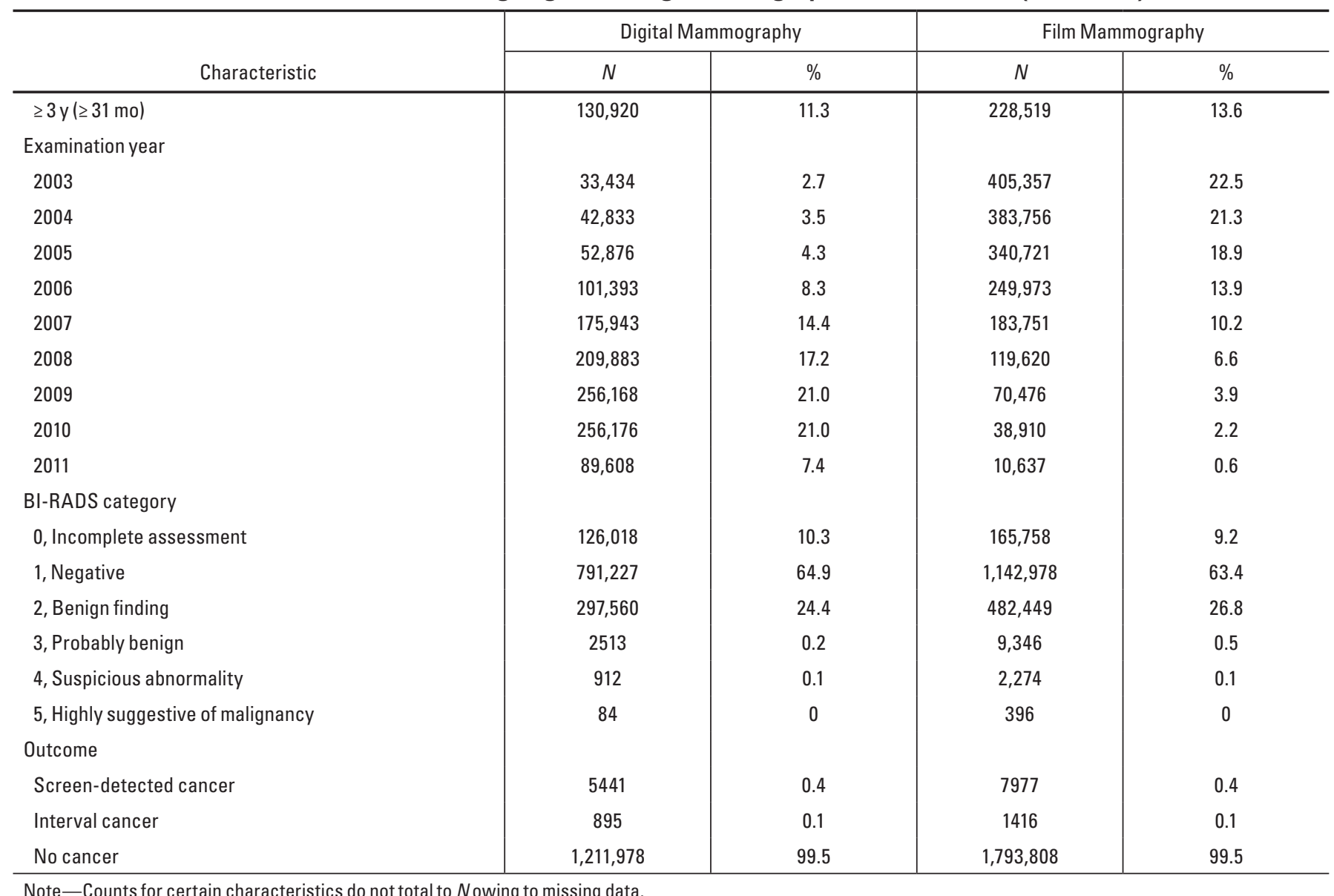

TABLE 2: Characteristics of Women With Screen-Detected and Interval Cancers by Imaging Modality: Breast Cancer Surveillance Consortium 2003-20II

\begin{tabular}{|c|c|c|c|c|c|c|c|c|}
\hline \multirow[b]{2}{*}{ Characteristic } & \multicolumn{4}{|c|}{ Screen-Detected Cancer $(n=13,418)$} & \multicolumn{4}{|c|}{ Interval Cancer ( $n=2311)$} \\
\hline & $N$ & $\%$ & $N$ & $\%$ & $N$ & $\%$ & $N$ & $\%$ \\
\hline No. of women ${ }^{a}$ & 5441 & 40.6 & 7977 & 59.4 & 895 & 38.7 & 1416 & 61.3 \\
\hline \multicolumn{9}{|l|}{ Age at examination (y) } \\
\hline $40-49$ & 1004 & 18.5 & 1277 & 16.0 & 225 & 25.1 & 347 & 24.5 \\
\hline $60-69$ & 1537 & 28.2 & 2134 & 26.8 & 223 & 24.9 & 365 & 25.8 \\
\hline $70-79$ & 1010 & 18.6 & 1573 & 19.7 & 131 & 14.6 & 227 & 16.0 \\
\hline$\geq 80$ & 388 & 7.1 & 636 & 8.0 & 53 & 5.9 & 67 & 4.7 \\
\hline \multicolumn{9}{|l|}{ Race, ethnicity } \\
\hline American Indian, Alaska Native & 10 & 0.2 & 57 & 0.8 & 4 & 0.5 & 14 & 1.0 \\
\hline Hispanic & 92 & 1.8 & 151 & 2.0 & 14 & 1.7 & 20 & 1.5 \\
\hline Other & 174 & 3.4 & 532 & 7.0 & 18 & 2.1 & 76 & 5.7 \\
\hline
\end{tabular}


Henderson et al.

TABLE 2: Characteristics of Women With Screen-Detected and Interval Cancers by Imaging Modality: Breast Cancer Surveillance Consortium 2003-20II (continued)

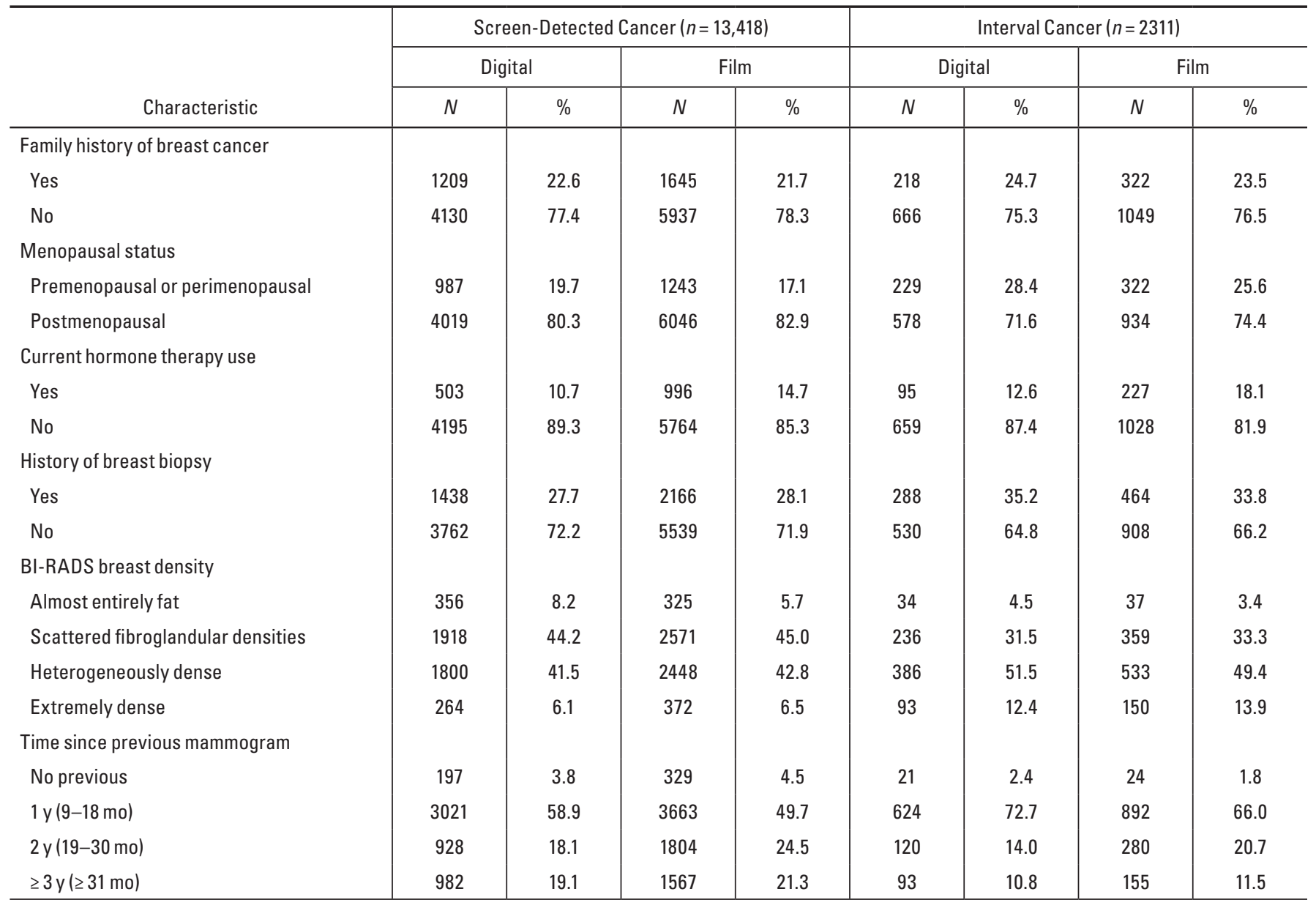

a Percentages are for the row by screen-detected and interval cancer groups. All other percentages are column percentages.

TABLE 3: Rates of Cancer per 1000 Mammograms by Tumor Characteristics, Mode of Detection, and Imaging Modality: Breast Cancer Surveillance Consortium 2003-20II

\begin{tabular}{|c|c|c|c|c|c|c|c|c|c|c|c|c|}
\hline \multirow[b]{2}{*}{ Cancer Characteristic } & \multicolumn{6}{|c|}{ Screen-Detected Cancer $(n=13,418)$} & \multicolumn{6}{|c|}{ Interval Cancer $(n=2311)$} \\
\hline & $\begin{array}{c}\text { No. of } \\
\text { Cancers }\end{array}$ & $\mid \begin{array}{c}\text { Column } \\
\%\end{array}$ & $\begin{array}{c}\text { Rate per } \\
1000\end{array}$ & $\begin{array}{c}\text { No. of } \\
\text { Cancers }\end{array}$ & $\begin{array}{c}\text { Column } \\
\%\end{array}$ & $\begin{array}{c}\text { Rate per } \\
1000\end{array}$ & $\begin{array}{c}\text { No. of } \\
\text { Cancers }\end{array}$ & $\begin{array}{c}\text { Column } \\
\%\end{array}$ & $\begin{array}{c}\text { Rate per } \\
1000\end{array}$ & $\begin{array}{c}\text { No. of } \\
\text { Cancers }\end{array}$ & $\begin{array}{c}\text { Column } \\
\%\end{array}$ & $\begin{array}{c}\text { Rate per } \\
1000\end{array}$ \\
\hline Total $^{\mathrm{a}}$ & 5441 & 86 & 4.47 & 7977 & 85 & 4.42 & 895 & 14 & 0.73 & 1416 & 15 & 0.79 \\
\hline DCIS & 1638 & 30 & 1.34 & 1854 & 23 & 1.03 & 106 & 12 & 0.09 & 132 & 9 & 0.07 \\
\hline \multicolumn{13}{|c|}{ American Joint Committee on Cancer stage } \\
\hline I & 2313 & 63 & 1.90 & 3530 & 61 & 1.96 & 311 & 41 & 0.26 & 466 & 39 & 0.26 \\
\hline IIA & 780 & 21 & 0.64 & 1200 & 21 & 0.67 & 229 & 30 & 0.19 & 338 & 28 & 0.19 \\
\hline IIB & 334 & 9 & 0.27 & 552 & 10 & 0.31 & 103 & 14 & 0.08 & 162 & 13 & 0.09 \\
\hline III & 211 & 6 & 0.17 & 393 & 7 & 0.22 & 97 & 13 & 0.08 & 187 & 16 & 0.10 \\
\hline
\end{tabular}

(Table 3 continues on next page) 
Digital Versus Film-Screen Mammography

TABLE 3: Rates of Cancer per 1000 Mammograms by Tumor Characteristics, Mode of Detection, and Imaging Modality: Breast Cancer Surveillance Consortium 2003-20II (continued)

\begin{tabular}{|c|c|c|c|c|c|c|c|c|c|c|c|c|}
\hline \multirow[b]{2}{*}{ Cancer Characteristic } & \multicolumn{6}{|c|}{ Screen-Detected Cancer $(n=13,418)$} & \multicolumn{6}{|c|}{ Interval Cancer ( $n=2311)$} \\
\hline & $\begin{array}{c}\text { No. of } \\
\text { Cancers }\end{array}$ & $\underset{\%}{\text { Column }}$ & $\begin{array}{c}\text { Rate per } \\
1000\end{array}$ & $\begin{array}{c}\text { No. of } \\
\text { Cancers }\end{array}$ & $\underset{\%}{\text { Column }}$ & $\begin{array}{c}\text { Rate per } \\
1000\end{array}$ & $\begin{array}{c}\text { No. of } \\
\text { Cancers }\end{array}$ & $\mid \begin{array}{c}\text { Column } \\
\%\end{array}$ & $\begin{array}{c}\text { Rate per } \\
1000\end{array}$ & $\begin{array}{c}\text { No. of } \\
\text { Cancers }\end{array}$ & $\underset{\%}{\text { Column }}$ & $\begin{array}{c}\text { Rate per } \\
1000\end{array}$ \\
\hline \multicolumn{13}{|c|}{$\begin{array}{l}\text { Surveillance, Epidemiology, and End } \\
\text { Results summary stage }\end{array}$} \\
\hline Distant & 36 & 1 & 0.03 & 68 & 1 & 0.04 & 23 & 3 & 0.02 & 49 & 4 & 0.03 \\
\hline Unknown & 123 & 3 & 0.10 & 260 & 4 & 0.14 & 22 & 3 & 0.02 & 53 & 4 & 0.03 \\
\hline \multicolumn{13}{|l|}{ Tumor size (mm) } \\
\hline$\leq 10$ & 1184 & 34 & 0.97 & 1778 & 32 & 0.99 & 124 & 17 & 0.10 & 193 & 16 & 0.11 \\
\hline \multicolumn{13}{|l|}{ Nodal status } \\
\hline Negative & 2917 & 78 & 2.39 & 4534 & 76 & 2.51 & 504 & 65 & 0.41 & 757 & 61 & 0.42 \\
\hline Positive & 812 & 22 & 0.67 & 1425 & 24 & 0.79 & 270 & 35 & 0.22 & 493 & 39 & 0.27 \\
\hline Unknown & 74 & 2 & 0.06 & 164 & 3 & 0.09 & 15 & 2 & 0.01 & 34 & 3 & 0.02 \\
\hline \multicolumn{13}{|l|}{ Grade } \\
\hline 1 & 1142 & 32 & 0.94 & 1635 & 29 & 0.91 & 153 & 21 & 0.13 & 235 & 21 & 0.13 \\
\hline 2 & 1597 & 45 & 1.31 & 2436 & 44 & 1.35 & 313 & 43 & 0.26 & 455 & 40 & 0.25 \\
\hline 3 & 838 & 23 & 0.69 & 1512 & 27 & 0.84 & 269 & 37 & 0.22 & 447 & 39 & 0.25 \\
\hline Unknown & 226 & 6 & 0.19 & 540 & 9 & 0.30 & 54 & 7 & 0.04 & 147 & 11 & 0.08 \\
\hline Negative & 804 & 22 & 0.66 & 1373 & 25 & 0.76 & 227 & 30 & 0.19 & 393 & 35 & 0.22 \\
\hline Unknown & 201 & 5 & 0.16 & 728 & 12 & 0.40 & 41 & 5 & 0.03 & 158 & 12 & 0.09 \\
\hline \multicolumn{13}{|l|}{ ERBB $^{\mathrm{b}}{ }^{\mathrm{b}}$} \\
\hline Positive & 316 & 12 & 0.26 & 549 & 15 & 0.30 & 76 & 14 & 0.06 & 125 & 18 & 0.07 \\
\hline Negative & 2243 & 88 & 1.84 & 2995 & 85 & 1.66 & 478 & 86 & 0.39 & 574 & 82 & 0.32 \\
\hline Unknown & 1244 & 33 & 1.02 & 2579 & 42 & 1.43 & 235 & 30 & 0.19 & 585 & 46 & 0.32 \\
\hline \multicolumn{13}{|l|}{ Triple negative } \\
\hline Yes & 210 & 8 & 0.17 & 287 & 8 & 0.17 & 78 & 14 & 0.06 & 103 & 15 & 0.06 \\
\hline No & 2333 & 92 & 1.91 & 3148 & 92 & 1.91 & 473 & 86 & 0.39 & 578 & 85 & 0.32 \\
\hline Unknown & 1260 & 33 & 1.03 & 2688 & 44 & 1.03 & 238 & 30 & 0.20 & 603 & 47 & 0.33 \\
\hline
\end{tabular}

aPercentages are for the row. All other percentages are column percentages.

bAlso known as known as HER2 or HER2/neu.

with film mammography (1.34 vs 1.03 per 1000 examinations). Yet there was little difference in invasive tumor features for digital or film screen-detected cancers. Interval cancers diagnosed after digital mammography were also slightly more likely to be DCIS but with few differences in invasive tumor features.
Relative Risk of Unfavorable Tumor Characteristics

The adjusted ORs of having unfavorable tumor characteristics were significantly dif- 
ferent for digital versus film mammography among women with interval cancers but not among women with screen-detected cancers (Table 4). For women with interval cancers, cancers diagnosed after digital mammography were slightly less likely to have unfavorable tumor features than were cancers diagnosed after film mammography. For example, interval cancers not seen on digital mammograms were $31 \%$ less likely than interval cancers not seen on film mammograms to present at AJCC stage IIB or higher (adjusted OR, 0.69; 95\% CI, 0.52-0.93; rate, 0.12 vs 0.18 per 1000 examinations), $22 \%$ less likely to be regional or distant disease (adjusted OR, 0.78; 95\% CI, 0.64-0.95; rate 0.23 vs 0.28 per 1000 examinations), $22 \%$ less likely to have positive nodal status (adjusted OR, 0.78; 95\% CI, 0.64-0.95; rate, 0.22 vs 0.27 per 1000 examinations), and $29 \%$ less likely to present with estrogen receptor-negative tumors (adjusted OR, 0.71; 95\% CI, 0.56-0.91; rate, 0.13 vs 0.16 per 1000 examinations).
In contrast, the adjusted ORs of having favorable tumor characteristics (early stage, smaller tumor size, negative nodal status, lower grade, and estrogen receptor-positive tumors) were not significantly different for digital versus film mammography for screendetected or interval cancers. The one exception was among screen-detected cancers, in which the adjusted OR of having DCIS versus invasive disease was 1.30 (95\% CI, 1.15-1.48), indicating that DCIS is more frequently detected on digital than on film mammograms.

\section{Discussion}

Our findings revealed a similar proportion of interval cancers among women screened with digital mammography and those screened with film mammography. This proportion is similar to the $13.8 \%$ reported in the Ontario Breast Screening Program [1]. We also found that the rates of screen-detected and interval cancers were similar across modalities. Our rates are substantially lower than those found in a 2014 study conducted in The Netherlands by Nederend et al. [9], who reported an interval cancer rate for digital mammography of 2.0 per 1000 examinations versus 1.7 per 100 for film mammograms. Hoff et al. [16] reported similar rates of screen-detected invasive cancer and interval cancer but higher rates of screen-detected DCIS on digital than on film mammograms. Studies from Ireland, The Netherlands, and Norway [17-19] showed increased cancer detection rates with digital mammography, whereas studies from Spain, the United Kingdom, and the United States showed similar cancer detection rates for digital and film mammography [2, 8, 17-21].

As in previous studies based on film mammography [22-24], we found that interval cancers were more likely than screen-detected cancers to have unfavorable tumor characteristics. In particular, interval cancers had a higher stage, larger size, and greater frequencies of positive lymph node involvement and estrogen receptor-negative status. Our results also agree with those of a study

TABLE 4: Odds Ratios of Having Tumor Characteristics With Worse Prognosis (Relative to Better Prognosis or No Cancer) and Better Prognosis (Relative to Worse Prognosis or No Cancer) for Digital Versus Film Mammography: Breast Cancer Surveillance Consortium 2003-20II

\begin{tabular}{|c|c|c|c|c|}
\hline \multirow[b]{2}{*}{ Cancer Characteristic } & \multicolumn{2}{|c|}{ Screen-Detected Cancers } & \multicolumn{2}{|c|}{ Interval Cancers } \\
\hline & Unadjusted Odds Ratio & Adjusted Odds Ratio ${ }^{a}$ & Unadjusted Odds Ratio & Adjusted Odds Ratio ${ }^{a}$ \\
\hline All & & & & \\
\hline Cancer diagnosis & $1.01(0.94-1.09)$ & $1.06(0.97-1.16)$ & $0.94(0.81-1.08)$ & $0.93(0.78-1.10)$ \\
\hline Unfavorable prognosis & & & & \\
\hline Invasive cancers & $0.92(0.85-0.90)$ & $0.98(0.89-1.07)$ & $0.91(0.79-1.04)$ & $0.90(0.77-1.06)$ \\
\hline AJCC stage IIB or higher & $0.85(0.70-1.02)$ & $1.02(0.85-1.23)$ & $0.82(0.68-1.01)$ & $0.69(0.52-0.93)$ \\
\hline Regional or distant SEER summary stage ${ }^{b}$ & $0.84(0.74-0.95)$ & $1.07(0.93-1.24)$ & $0.80(0.68-0.94)$ & $0.78(0.64-0.95)$ \\
\hline Tumor size $>20 \mathrm{~mm}$ & $0.87(0.76-1.00)$ & $0.96(0.81-1.14)$ & $0.94(0.78-1.13)$ & $0.83(0.66-1.04)$ \\
\hline Positive nodal status & $0.84(0.75-0.95)$ & $1.07(0.93-1.24)$ & $0.81(0.69-0.95)$ & $0.78(0.64-0.95)$ \\
\hline Grade 3 & $0.82(0.73-0.92)$ & $0.99(0.85-1.15)$ & $0.89(0.72-1.09)$ & $0.84(0.67-1.06)$ \\
\hline Estrogen receptor negative & $0.86(0.73-1.00)$ & $0.96(0.78-1.18)$ & $0.81(0.64-1.03)$ & $0.71(0.56-0.91)$ \\
\hline Favorable prognosis & & & & \\
\hline DCIS & $1.31(1.17-1.46)$ & $1.30(1.15-1.48)$ & $1.19(0.88-1.60)$ & $1.19(0.71-1.98)^{c}$ \\
\hline AJCC stage IIA or earlier & $0.97(0.88-1.06)$ & $0.99(0.90-1.09)$ & $0.99(0.86-1.15)$ & $1.03(0.85-1.24)$ \\
\hline Local SEER summary stage $\mathrm{e}^{\mathrm{c}}$ & $0.96(0.88-1.04)$ & $0.95(0.87-1.05)$ & $1.01(0.86-1.18)$ & $0.99(0.80-1.24)$ \\
\hline Tumor size $\leq 20 \mathrm{~mm}$ & $0.95(0.86-1.05)$ & $1.00(0.90-1.11)$ & $0.93(0.79-1.09)$ & $0.97(0.80-1.19)$ \\
\hline Negative nodal status & $0.95(0.88-1.03)$ & $0.96(0.87-1.05)$ & $0.99(0.84-1.16)$ & $0.97(0.78-1.21)$ \\
\hline Grade I or II & $1.00(0.91-1.09)$ & $1.01(0.90-1.12)$ & $1.00(0.84-1.19)$ & $1.01(0.83-1.24)$ \\
\hline Estrogen receptor positive & $1.00(0.91-1.10)$ & $0.97(0.88-1.07)$ & $1.04(0.90-1.21)$ & $0.98(0.81-1.18)$ \\
\hline
\end{tabular}

Note-Values in parentheses are $95 \% \mathrm{Cl}$. Bold type indicates statistically significant value. AJCC $=$ American Joint Committee on Cancer, SEER $=$ Surveillance, Epidemiology, and End Results, DCIS = ductal carcinoma in situ.

${ }^{a}$ Adjusted for current hormone therapy use, age, race and ethnicity, screening interval, examination year, and Breast Cancer Surveillance Consortium registry.

bSEER summary stages are local, regional, and distant.

'Models adjusted for screening interval or race did not converge. 
conducted with data from the Dutch Microarray in Node-Negative Disease May Avoid Chemotherapy trial. That study [25] showed that tumor characteristics of cancers screen detected with digital mammography were similar to those of cancers detected with film mammography and that interval cancers diagnosed after screening with film mammography had more unfavorable characteristics than cancers diagnosed after digital mammography. We add to the existing literature in that previous work focused on screendetected and interval cancers based on film mammographic findings and our study includes more than 3800 cancers diagnosed after digital mammography.

Among women with interval cancer, adjusted ORs of unfavorable tumor characteristics were lower for digital than for film mammography. This finding was not observed for screen-detected cancers. A 2014 study conducted in The Netherlands [9] compared characteristics of interval cancers among 63,182 women screened with digital mammography and 60,770 women screened with film mammography between 2008 and 2010. That study did not show differences in breast density, tumor size, lymph node status, or hormone receptor status between digitaland film-detected interval cancers. It is possible that the difference between the film versus digital interval cancers we observed and the findings of Nederend et al. [9] reflects the different interval cancer rates in The Netherlands and the United States or that Nederend et al. defined interval cancers on the basis of 2 years of follow-up.

In our study we found almost identical overall cancer detection rates of 5.20 and 5.21 per 1000 examinations for digital and film mammography. Interestingly, digital mammography showed more instances of DCIS. The meaning of this finding is unclear, but one possibility is that the types of DCIS found at digital mammography may lead to fewer interval cancers with poor prognostic characteristics. We do not believe this is the case because mammographically detected DCIS has a less than $10 \%$ chance of being associated with a subsequent invasive cancer in 10 years, and most subsequent invasive cancers are not as aggressive as the interval cancers in our study [25]. This unexplained and interesting finding deserves more study.

The strengths of our study include the ability to examine both digital and film mammograms in a national cohort of screen- ing mammograms from community-based practices. The BCSC dataset contains a large number of screen-detected and interval cancers even after stratification by imaging modality. Our study also had limitations, however. First, in the BCSC data, we were unable to determine whether the interval cancers were true interval cancers or missed cancers that were visible on the screening images. Second, we had incomplete data on ERBB2 status (also known as HER2 or HER2/neu), another important prognostic factor. Because the SEER data more comprehensively capture ERBB2 status, the lack of data remains a problem for many studies conducted with state cancer registries.

Our study results suggest that the transition to digital mammography in the United States has not reduced the interval cancer rate. Interval cancers constitute approximately $15 \%$ of breast cancers for both digital and film mammography. However, interval cancers detected after negative results of a digital examination had a lower rate of unfavorable characteristics than those detected after negative results of a film examination, which may improve treatment outcomes. The pathologic findings are similar for screen-detected cancers whether the modality is digital or film. As technologies in breast imaging change in the future, a study similar to this one that compares the pathologic features of cancers detected with digital mammography with those of cancers detected with tomosynthesis will be important to determine whether screen-detected and interval cancers vary in a clinically meaningful way between these two modalities.

\section{Acknowledgments}

We thank the participating women, mammographic facilities, and radiologists for the data they provided for this study.

\section{References}

1. Kirsh VA, Chiarelli AM, Edwards SA, et al. Tumor characteristics associated with mammographic detection of breast cancer in the Ontario breast screening program. J Natl Cancer Inst 2011; 103:942-950

2. Domingo L, Romero A, Belvis F, et al. Differences in radiological patterns, tumour characteristics and diagnostic precision between digital mammography and screen-film mammography in four breast cancer screening programmes in Spain. Eur Radiol 2011; 21:2020-2028

3. Raja MA, Hubbard A, Salman AR. Interval breast cancer: is it a different type of breast cancer?
Breast 2001; 10:100-108

4. Vitak B, Olsen KE, Manson JC, Arnesson LG, Stal O. Tumour characteristics and survival in patients with invasive interval breast cancer classified according to mammographic findings at the latest screening: a comparison of true interval and missed interval cancers. Eur Radiol 1999; 9:460-469

5. Duijm LE, Groenewoud JH, de Koning HJ, et al. Delayed diagnosis of breast cancer in women recalled for suspicious screening mammography. Eur J Cancer 2009; 45:774-781

6. Hofvind S, Geller B, Skaane P. Mammographic features and histopathological findings of interval breast cancers. Acta Radiol 2008; 49:975-981

7. U.S. Department of Human Services, U.S. Food and Drug Administration website. Radiation-emitting products: MQSA national statistics. www.fda. gov/Radiation-EmittingProducts/Mammography QualityStandardsActandProgram/FacilityScorecard/ ucm113858.htm. Accessed March 12, 2014

8. Kerlikowske K, Hubbard RA, Miglioretti DL, et al. Comparative effectiveness of digital versus film-screen mammography in community practice in the United States: a cohort study. Ann Intern Med 2011; 155:493-502

9. Nederend J, Duijm LE, Louwman MW, et al. Impact of the transition from screen-film to digital screening mammography on interval cancer characteristics and treatment: a population based study from The Netherlands. Eur J Cancer 2014; 50:31-39

10. Ballard-Barbash R, Taplin SH, Yankaskas BC, et al. Breast Cancer Surveillance Consortium: a national mammography screening and outcomes database. AJR 1997; 169:1001-1008

11. Breast Cancer Surveillance Consortium website. BCSC glossary of terms. breastscreening.cancer. gov/data/bcsc_data_definitions.pdf. Updated September 16, 2009. Accessed May 18, 2015

12. Rosenberg RD, Yankaskas BC, Abraham LA, et al. Performance benchmarks for screening mammography. Radiology 2006; 241:55-66

13. Taplin SH, Ichikawa LE, Kerlikowske K, et al. Concordance of breast imaging reporting and data system assessments and management recommendations in screening mammography. Radiology 2002; 222:529-535

14. American College of Radiology. Breast Imaging Reporting and Data System (BI-RADS), 3rd ed. Reston, VA: American College of Radiology, 1998

15. Geller BM, Ichikawa LE, Buist DS, et al. Improving the concordance of mammography assessment and management recommendations. Radiology 2006; 241:67-75

16. Hoff SR, Abrahamsen AL, Samset JH, Vigeland E, Klepp O, Hofvind S. Breast cancer: missed interval and screening-detected cancer at full-field digital mammography and screen-film mammography-results from a retrospective review. Radiology 2012; 


\section{Henderson et al.}

264:378-386

17. Hambly NM, McNicholas MM, Phelan N, Hargaden GC, O'Doherty A, Flanagan FL. Comparison of digital mammography and screen-film mammography in breast cancer screening: a review in the Irish breast screening program. AJR 2009; 193:1010-1018

18. Karssemeijer N, Bluekens AM, Beijerinck D, et al. Breast cancer screening results 5 years after introduction of digital mammography in a population-based screening program. Radiology 2009; 253:353-358

19. Vigeland E, Klaasen H, Klingen TA, Hofvind S, Skaane P. Full-field digital mammography compared to screen film mammography in the prevalent round of a population-based screening pro- gramme: the Vestfold County Study. Eur Radiol 2008; 18:183-191

20. Vinnicombe S, Pinto Pereira SM, McCormack VA, Shiel S, Perry N, Dos Santos Silva IM. Fullfield digital versus screen-film mammography: comparison within the UK breast screening program and systematic review of published data. Radiology 2009; 251:347-358

21. Pisano ED, Gatsonis C, Hendrick E, et al. Diagnostic performance of digital versus film mammography for breast-cancer screening. $N$ Engl J Med 2005; 353:1773-1783

22. Porter PL, El-Bastawissi AY, Mandelson MT, et al. Breast tumor characteristics as predictors of mammographic detection: comparison of inter- val- and screen-detected cancers. J Natl Cancer Inst 1999; 91:2020-2028

23. Hakama M, Holli K, Isola J, et al. Aggressiveness of screen-detected breast cancers. Lancet 1995; 345:221-224

24. Tabár L, Faberberg G, Day NE, Holmberg L. What is the optimum interval between mammographic screening examinations? An analysis based on the latest results of the Swedish twocounty breast cancer screening trial. Br J Cancer 1987; 55:547-551

25. Drukker CA, Schmidt MK, Rutgers EJ, et al. Mammographic screening detects low-risk tumor biology breast cancers. Breast Cancer Res Treat 2014; 144:103-111 